\title{
An Overview of the Role of Adipokines in Cardiometabolic Diseases
}

\author{
Tahereh Farkhondeh ${ }^{1,2}$, Silvia Llorens ${ }^{3} \mathbb{D}$, Ali Mohammad Pourbagher-Shahri ${ }^{\mathbb{D}}$, \\ Milad Ashrafizadeh ${ }^{4,5}$ (D), Marjan Talebi ${ }^{6}$, Mehdi Shakibaei ${ }^{\circ} *$ (D) \\ and Saeed Samarghandian $8, * \mathbb{D}$
}

1 Medical Toxicology and Drug Abuse Research Center (MTDRC), Birjand University of Medical Sciences, Birjand 9717853577, Iran; farkhondeh2324@gmail.com

2 Faculty of Pharmacy, Birjand University of Medical Sciences, Birjand 9717853577, Iran; ali.pourbagher.shahri@gmail.com

3 Department of Medical Sciences, Faculty of Medicine of Albacete, Centro Regional de Investigaciones Biomédicas (CRIB), University of Castilla-La Mancha, 02008 Albacete, Spain; silvia.llorens@uclm.es

4 Faculty of Engineering and Natural Sciences, Sabanci University, Orta Mahalle, Üniversite Caddesi No. 27, Orhanl1, Tuzla, Istanbul 34956, Turkey; dvm.milad73@yahoo.com

5 Sabanci University Nanotechnology Research and Application Center (SUNUM), Tuzla, Istanbul 34956, Turkey

6 Department of Pharmacognosy, School of Pharmacy, Shahid Beheshti University of Medical Sciences, Tehran 1996835113, Iran; talebi.m@sbmu.ac.ir

7 Musculoskeletal Research Group and Tumour Biology, Chair of Vegetative Anatomy, Institute of Anatomy, Faculty of Medicine, Ludwig-Maximilian-University Munich, Pettenkoferstrasse 11, D-80336 Munich, Germany

8 Noncommunicable Diseases Research Center, Neyshabur University of Medical Sciences, Neyshabur 9318614139, Iran

* Correspondence: mehdi.shakibaei@med.uni-muenchen.de (M.S.); samarghandians1@nums.ac.ir (S.S.); Tel.: +49-89-2180-72624/72625 (M.S.); +98-915-1200945 (S.S.)

Received: 8 October 2020; Accepted: 6 November 2020; Published: 9 November 2020

check for updates

\begin{abstract}
Obesity as an independent risk factor for cardiovascular diseases (CVDs) leads to an increase in morbidity, mortality, and a shortening of life span. The changes in heart structure and function as well as metabolic profile are caused by obese people, including those free of metabolic disorders. Obesity alters heart function structure and affects lipid and glucose metabolism, blood pressure, and increase inflammatory cytokines. Adipokines, specific cytokines of adipocytes, are involved in the progression of obesity and the associated co-morbidities. In the current study, we review the scientific evidence on the effects of obesity on CVDs, focusing on the changes in adipokines. Several adipokines have anti-inflammatory and cardioprotective effects comprising omentin, apelin, adiponectin, and secreted frizzled-related protein (Sfrp-5). Other adipokines have pro-inflammatory impacts on the cardiovascular system and obesity including leptin, tumor necrosis factor (TNF), retinol-binding protein4 (RBP-4), visfatin, resistin, and osteopontin. We found that obesity is associated with multiple CVDs, but can only occur in unhealthy metabolic patients. However, more studies should be designed to clarify the association between obesity, adipokine changes, and the occurrence of CVDs.
\end{abstract}

Keywords: obesity; cardiovascular disease; metabolic diseases; adipokines

\section{Introduction}

Obesity is already a global pandemic problem, and thus a significant threat to public health. Its worldwide incidence has doubled in recent years. Obesity has become one of the leading causes of 
death due to numerous co-morbidities [1,2]. These obesity-related diseases include cardiovascular diseases (CVDs), type 2 diabetes (DM2), dyslipidemia, and hypertension [3].

Adipose tissue, commonly referred to as 'fat', is a type of loose connective tissue that consists of two components, adipocytes and stromal vascular fraction (SVF). SVF consists of pre-adipocytes, immune system cells, mesenchymal cells, fibroblasts, endothelial precursor cells, smooth muscle cells, blood cells, and blood vessels [4].

CVDs are the leading cause of mortality in the obese population. The associated mechanisms and conditions of obesity, such as excessive accumulation of adipose tissue (obesity), are physiopathologically relevant as they can increase the risk of CVDs independently of other pathologies and alter the structure and function of the myocardium [5]. They can also influence other diseases' progression and severity, such as dyslipidemia, diabetes, and hypertension [6].

Adipose tissue spreads throughout the body, though it is mainly found in visceral and subcutaneous depots [7]. Its function is essential for health; it specializes in the synthesis and storage of triglycerides in lipid droplets (lipogenesis) and the release of fatty acids into the systemic circulation (lipolysis) during periods of scarcity. Adipose tissue is not only an energy-preserving tissue but can also release numerous substances that act in a paracrine, autocrine, endocrine, and vasocrine way to maintain metabolic homeostasis. These substances include immunomodulatory proteins, collectively known as 'adipokines' or 'adipocytokines' [8]. The change in the expression of adipokines is probably the cause of chronic low-grade inflammation in obesity. Effects of adipokines on the inflammatory system have been reported in clinical and experimental studies, and this could be a factor influencing the pathogenesis of obesity-associated diseases such as CVD [9]. Metabolic disorders in different adipose tissue depots contribute to the fact that the profile of secretory adipokines varies between individuals, although in obesity the production of pro-inflammatory adipokines is generally favored despite their depot location $[10,11]$. The pro-inflammatory adipokines (i.e., TNF- $\alpha$, Leptin, resistin, retinol-4 transporter protein (RBP4), lipocalin 2, angiopoietin-related protein 2 (ANGPTL2), interleukins (IL-6, IL-18), among others) outweigh the anti-inflammatory mediator (i.e., adiponectin). This pathogenic adipokines profile has been reported to promote cardiometabolic syndrome and CVDs in obesity $[9,12,13]$.

Thus, understanding the links between obesity, cardiometabolic syndrome and CVDs, and the altered adipokines secretion profile is of great importance to developing new therapeutic strategies to treat obesity-related complications. This review collects scientific evidence from the last 5 years to discuss the triangle of obesity, cardiovascular disease, and cardiometabolic disorders, as well as several adipokines involved.

\section{Obesity, Metabolic Health, and Cardiovascular Diseases}

Metabolic syndrome (MS) or syndrome $\mathrm{X}$ is also known as a cardiometabolic syndrome. MS is a cluster of metabolic and cardiovascular symptoms strongly associated with DM2 and is very frequently associated with hypertension, dyslipidemia, atherosclerosis, and especially obesity. Furthermore, MS is defined by the presence of hyperglycemia (fasting plasma glucose levels $\geq 5.6 \mathrm{mmol} / \mathrm{L}$ ), central obesity (waist circumference $\geq 90 \mathrm{~cm}$ for men, and $\geq 80 \mathrm{~cm}$ for women), low high-density lipoproteins (HDL) level ( $<1.03 \mathrm{mmol} / \mathrm{L}$ for men, $<1.29 \mathrm{mmol} / \mathrm{L}$ for women), high total triglyceride levels $(\geq 1.7 \mathrm{mmol} / \mathrm{L})$, and elevated blood pressure $(\geq 130 / 85 \mathrm{mmHg})$, highlighting that MS is a strong risk factor for the development of CVDs and DM2 [14].

Some evidence shows a complex relationship network between DM2, obesity, and CVDs. Thus, overweight/obesity is a risk factor for CVDs in DM2 individuals, and indeed individuals with DM2 and CVDs have a high probability of being overweight. Furthermore, obesity in DM2 patients increases the severity of metabolic disorders, which may further increase the risk of CVDs [15]. Animal models of obesity have shown metabolic disorders, including hyperlipidemia and hepatic dysfunction [16]. Indeed, a study in Bangladesh's population showed that both overweight and obese individuals had increased serum insulin, triglyceride, homocysteine, insulin resistance, and atherogenic markers compared to normal-weight individuals [17]. 
Substantial weight gain is harmful to metabolic health and is also a risk factor for developing CVDs, even in young individuals. Moreover, overweight and obesity in childhood can increase the risk of cardiometabolic diseases. Overweight and obese children in free-living conditions are hyperglycemic [18]. The presence of insulin resistance in these children also aggravated the already established hyperglycemia, making them more susceptible to development CVDs and DM2 [18]. Remarkably, abnormal glucose metabolism and dyslipidemia have been observed in obese adolescents [19]. These hazardous effects can also be felt later in life, regardless of race, gender, and obesity status [20].

Insulin resistance is a central mechanism that connects all components of MS, regardless of whether they are tissue-specific or cell type-specific. Also, insulin resistance contributes to the CVDs promoting atherogenesis and plaque progression via multiple mechanisms, including changes in classic risk factors of CVDs and downregulation of insulin signaling pathways [21]. It is still unclear whether insulin resistance in obese individuals directly contributes to this by altering cardiac morphology and ventricular function. To date, studies in obese individuals have not shown a significant relationship between insulin resistance and left ventricular mass and index [22]. More future research is needed to clarify the mechanism behind morphological and mechanical alterations of the heart in obesity.

The state of metabolic health can be affected by the hormonal disorder, so the hormonal differences between the sexes determine their respective metabolic health. Alterations in hormone levels impair metabolic health, but to varying degrees depending on gender, leading to different phenotypic and metabolic characteristics in gender-specific obesity. For example, overweight/obese men have an increased lean mass, resting metabolic rate, and serum triglycerides levels, whereas women have an increased ratio of fat in body composition, fat mass, HDL-C, and leptin [23].

Also, anthropometric measurements are used to assess obesity and the primary assessment starts with the body mass index (BMI) as a marker of obesity. Other anthropometric indices are required to describe the distribution of obesity, such as waist circumference, skinfold, arm circumference, waist-to-hip ratio, and the waist-to-stature ratio, among others [24]. Also, these indices predict CVDs risk. One study showed that arm circumference values in adolescents were associated with the elevation of fasting insulin in men. In women, body mass values were associated with increased insulin and inflammation scores [19].

\section{Obesity and Cardiovascular Diseases}

The best known and most modifiable risk factors for CVDs include elevated blood pressure, hypercholesterolemia, diabetes, sedentary lifestyle, obesity, inappropriate diet, and smoking [25,26]. Moreover, experimental studies have shown an association between obesity with systemic hypertension and left ventricular hypertrophy (LVH) [16]. Of particular interest are studies showing that there is a close relationship between body mass and CVDs as even a slight increase in BMI significantly raise the risk of CVDs in the later years $[27,28]$, and it has been observed that obese people with a higher risk of CVDs have a higher body fat percentage [29].

Also, obesity has significantly affected cardiac morphology and ventricular function [30,31]. It has also been shown that increased cardiac output and hypertension have been suggested as the mechanisms responsible for the development of $\mathrm{LVH}$, decreased systolic function, and disturbed relaxation [32]. These changes usually occur over a long time and are regardless of the degree of obesity $[9,33]$. Interestingly, experimental studies have shown a positive correlation between epicardial and visceral fat mass with diastolic dysfunction [34]. It was further observed that following the development of obesity, the heart's left ventricular function is impaired in animal models [35]. However, clinical investigations have not found an association between obesity and altered cardiac morphology and ventricular function [22].

Heart failure is higher in severely obese people [6,36], but once heart failure is established, a phenomenon called the 'obesity paradox' might be observed. The obesity paradox exhibits as obese and overweight patients with heart failure have a better prognosis than normal or underweight 
patients [37]. However, individuals with different degrees of obesity have marked differences in their prognosis of heart failure. Besides, the non-linear relation between the increasing degree of obesity and cardiovascular outcome of chronic heart failure has been shown [38]. A recent study showed that in acute heart failure patients the best short-term prognosis was seen in severely obese patients (BMI around $40 \mathrm{~kg} / \mathrm{m}^{2}$ ) and the worst prognosis in the normal weight patients [39].

Obesity is also associated with atrial fibrillation. Indeed this arrhythmia is one of the most common arrhythmias in obese people [40]. A report based on the Framingham study showed that after adjustment for CVDs risk factors and the occurrence of interim myocardial infarction or heart failure, when the BMI increased by 1 unit, the atrial fibrillation increased by $4 \%$. Also, the presence of obesity, regardless of its severity, increased the risk of atrial fibrillation by $50 \%$ [41].

It is known that different types of adipose tissue contribute differently to the effects of obesity. Depending on their location, adipose tissues consists of (A) subcutaneous adipose tissue (under the skin and stores $\sim 80 \%$ of total body fat), and (B) intra-abdominal adipose tissues ( $20 \%$ of total body fat) which consists of two parts: visceral adipose tissue (around the digestive organs) and retroperitoneal depot (around the kidney) [7]. These adipose tissue depots are remarkable for their enormous physiopathological relevance. The visceral adipose tissue is positively correlated with cardiovascular and cardiometabolic risk factors, regardless of age and gender [42]. Conversely, it has been observed that large depots of subcutaneous lower-body adipose tissue have protective effects on cardiometabolic health. However, metabolic disorders in these depots contribute to the development of obesity and its co-morbidities [43].

It should be noted that the metabolic profile is not necessarily always correlated with the excess of body fat. Given the different distribution of CVDs in different spectrums of BMI, some phenotypes have been described for obesity: (1) metabolically healthy overweight/obese individuals who are somehow resistant or protected towards cardiovascular morbidity; and (2) metabolically unhealthy individuals who are either normal-weight or overweight/obese [44]. How various phenotypes of obesity affect the risk of CVDs are not fully understood. A study in white European men showed that metabolically healthy overweight/obese individuals had no increased risk of mortality compared to metabolically healthy normal-weight individuals despite insulin resistance and sub-clinical inflammation in a 20-year follow-up. However, insulin resistance was more common in overweight or obese individuals, even if they were metabolically healthy [45].

In addition, there are biochemical and anthropometric differences between metabolically unhealthy and metabolically healthy individuals with obese/overweight, including having lower indices of BMI, waist circumference, percentage of fat mass, blood glucose, triglycerides, and insulin levels, and higher HDL-C levels in the latter group [29].

It is assumed that metabolically healthy and obese/overweight, in short, are benign $[46,47]$. Accordingly, one study found no increase in the risk of CVDs in metabolically healthy obese/overweight phenotypes over 12 years [48]. In contrast, in a prospective study, metabolically healthy obese people in the Greek population developed an unhealthy metabolic status during the 10-year follow-up [49]. One possible way for the delayed rise of CVDs risk in these individuals is the accumulated effects of obesity on metabolic health over time.

There are few data on the resistance of metabolically healthy, overweight/obese individuals to cardiometabolic diseases. The fact that these patients have a high risk of developing cardiometabolic and CVDs underline the need for scheduled screening of these groups through appropriate modalities.

\section{Adipokines: Function and Mechanism}

Adipose tissue comprises one of the most diverse types of cells such as adipocytes, endothelial cells, mast cells, fibroblasts, various immune cells, stem cells, etc. Interestingly, more than 600 different types of adipokines are secreted from this tissue. Adipokines consist of hormones, cytokines, growth factors, vasodilators, and several other substances with a variety of functions including important signal molecules [50,51]. The most investigated adipokines are adiponectin, leptin, resistin, 
chemotactic protein 1 (MCP-1), TNF- $\alpha$, IL-6, IL-1 $\beta$, IL-10, and transforming growth factor (TGF)- $\beta$. Furthermore, the functions and molecular mechanisms behind the adipokines' effects are not fully clarified. Adipokines are involved in a variety of functions and can influence many different processes including modulation of energy and appetite, lipid and glucose metabolism, insulin function, endothelial cell function, inflammation, blood pressure, hemostasis, atherosclerosis, metabolic syndrome, etc. [52].

\section{Leptin}

Leptin is a peptide hormone produced and secreted by mature adipocytes from white adipose tissue including the subcutaneous adipose tissue. It consists of 167 amino acids and is encoded on chromosome 7 at the gene locus 128.24-128.26. Leptin can pass the blood-brain barrier and exerts its effect mainly in the area of the hypothalamus and is associated with the expansion of the total fatty tissue of the body. It has been reported that females have higher rates of leptin synthesis compared to males [53]. Leptin affects insulin regulation as its high levels reduce insulin secretion and its low levels stimulate insulin synthesis. Besides, leptin regulates lipid metabolism, hematopoiesis, and pancreatic $\beta$-cell function [54,55]. Leptin can affect peripheral adiposity and the central nervous system (CNS) to modulate cardiometabolic conditions. Leptin receptor-expressing cells and leptin receptor-mediated neural networks regulate the neuroendocrine output and sympathetic nervous function, leading to homeostasis of cardiometabolic condition and disruption of CNS leptin signaling causes metabolic disorders including obesity, type 2 diabetes, and hypertension [56].

Leptin controls food intake by binding to its receptor (LEPR) in the hypothalamus [56]. This leads to a reduced feeling of hunger or increased satiety [57]. It is in antagonistic redundancy to ghrelin a gastrointestinal hormone involved in the control of hunger and satiety [57]. Also, leptin appears to play a role in inflammatory processes and embryonic implantation. It has been reported that leptin increases pro-inflammatory cytokine expression in macrophages and T-lymphocytes, and stimulates inflammatory pathways such as JAK-STAT3, mitogen-activated protein kinases (MAPKs), and phosphatidylinositol-4,5-bisphosphate 3-kinase (PI3Ks). In addition, obesity is accompanied by leptin resistance ('hyperleptinemia') which leads to the activation of the immune cells [58]. Hyperleptinemia is associated with adipocyte dysfunction and ectopic depots in peripheral tissues and consequently insulin resistance. Individuals with leptin resistance consume more food and gain more weight [57]. Finally, it is generally accepted that leptin acts as a proinflammatory adipokine.

\section{Adiponectin}

Another adipokine, which is mainly produced by the subcutaneous adipose tissue, is adiponectin with 244 amino acids and a molecular weight of $28 \mathrm{kDa}$; the APMI gene encodes it on chromosome 3 q27 [59]. In contrast to leptin, the serum adiponectin levels are lower in obese individuals. Adiponectin exhibits a wide variety of effects, including insulin sensitivity increased; fatty acid oxidation in the adipose tissue; reducing glucose release from the liver; and raising glucose uptake and adipogenesis as well as glucose metabolism and free fatty acids oxidation in the skeletal muscles $[60,61]$.

Effects of adiponectin are facilitated through its receptors called AdipoR1 and AdipoR2. Both are found in the adipose tissue and liver; only the AdipoR1 is also found in the skeletal muscle $[62,63]$. The AdipoR1 contributes to adiponectin's metabolic activity by increasing the adenosine monophosphate kinase (AMPK) activity [64-66]. Adiponectin can exhibit an anti-diabetic function via the AdipoR2, e.g., its binding causes an increase in insulin sensitivity, which implies the peroxisome proliferator-activated receptor (PPAR)- $\alpha$ activation in the liver through of this receptor [65].

The serum concentration of adiponectin is reduced in obese subjects and patients with cardiometabolic disorders [64]. Adiponectin levels are elevated with weight loss and anti-diabetic drugs. Its secretion is decreased by inflammatory mediators, proposing that inflammation may be the main factor involving in the reduction of adiponektin levels in insulin-resistant and obese conditions [65]. 
It has been reported that this adipokine can also prevent atherosclerosis by inhibiting the migration of monocytes/macrophages to the vascular wall and preventing the formation of foam cells. It should be emphasized that adiponectin has selective anti-inflammatory effects, i.e., it reduces endothelial cell-induced inflammation by reducing the activation of the pro-inflammatory transcription factor NF-kB (nuclear factor kappa-light-chain-enhancer of activated B-cells) [67].

Overall, adiponectin possesses anti-inflammatory, anti-diabetic, and anti-atherogenic properties. As expected, a negative correlation between obesity and adiponectin has been observed [68].

\section{Resistin}

Resistin is a polypeptide with a molecular weight of $11.3 \mathrm{kDa}$ and 108 amino acids, including 11 cysteines, produced and released by adipocytes in rodents and mainly by macrophages, monocytes, and pre-adipocytes in humans [69]. The mouse resistin gene is located on chromosome 9 , though the human resistin gene (Retn) is situated on chromosome 19. Mouse and human resistin share $46.7 \%$ genomic DNA homology, $64.4 \%$ mRNA sequence resemblance, and $59 \%$ amino acids identity [70]. Resistin influences insulin homeostasis, but the relationship between its serum levels and DM2, insulin resistance, or obesity is unclear and an increase in resistin levels correlated with these pathologies is still questionable [71,72]. The suggested mechanism by which the resistin affects obesity and insulin homeostasis acts on target cells both via paracrine and endocrine signaling pathways and via its receptors [73].

Resistin has also been reported to cause insulin resistance and inflammatory response. Animal models have shown that resistin can inhibit AMPK in the liver and skeletal muscle that inhibits the insulin-signaling pathway, and it has been observed that resistin can bind to the toll-like 4 receptor in the hypothalamus and activate intracellular inflammatory responses pathways as the NFKB signaling pathway [73]. Additionally, resistin induces the activation of endothelial cells via elevating the endothelin 1 expression, the intercellular adhesion molecule (ICAM-1), and the vascular cell-adhesion molecule (VCAM-1), leading to atherosclerosis in humans [74]. Measuring the resistin in metabolically unhealthy and healthy obese individuals has shown controversial results. Resistin is shown to be an inflammatory marker in the case of atherosclerosis [75]. Resistin concentrations were found to be higher in metabolically unhealthy obese individuals compared to the metabolically healthy [76], while another study found no differences [77].

\section{Other Adipokines}

Other adipokines were involved in obesity-related CVDs and cardio-metabolic disorders. The group of pro-inflammatory cytokines including TNF- $\alpha$, IL-6, and IL-1 $\beta$ inhibit lipoprotein lipase in adipocytes, thereby increasing the lipolysis and secretion of circulating free fatty acids, leading to insulin resistance [78]. It has been reported, that one of the important anti-inflammatory adipokines in the IL-10. The IL-10 blocks pro-inflammatory cytokines such as TNF- $\alpha$, IL-6, IL-1 $\beta$ and elevates anti-inflammatory cytokines such as IL-1R $\alpha[79,80]$. Besides, chronic inflammation in obesity leads to alterations in serum IL levels, which decreases IL-10 and increases IL-1 $\beta$ [81].

The transforming growth factor- $\beta$ (TGF- $\beta$ ) is another adipokine belonging to the growth-factor family and is capable of modulating cell proliferation, differentiation, cell adhesion, migration, and death. The TGF- $\beta$ levels in adipose tissue have been reported to be associated with severe obesity $[82,83]$. The role of TGF $\beta$ in obesity is controversial and not fully understood. While TGF- $\beta$ is associated with obesity in animal models and humans, it decreases the adipogenesis process in cell culture models (3T3-F442A cells) [81].

A recently identified adipokine called S100A4 has been shown to correlate with metabolic complications of excess or dysfunctional subcutaneous white adipose tissue [84]. S100A4 is related to subcutaneous white adipose tissue and insulin resistance inflammation/adipocyte hypertrophy which is BMI-independent [85]. Moreover, S100A4 inhibits obesity, diminishes the inflammatory responses, and activates the protein kinase B (Akt) signaling [86]. Retinol-binding protein (RBP4) is another 
adipokine that is elevated in obesity and causes insulin resistance [87]. Vaspin and omentin are two anti-inflammatory adipokines that ameliorate insulin resistance; visfatin and lipocalin are two other pro-inflammatory adipokines that stimulate TNF- $\alpha$ activity [88]; and Zinc-a2-glycoprotein (ZAG) possesses desirable effects on inflammation and regulates lipid and glucose metabolism [89].

In vitro and in vivo studies demonstrated that secreted frizzled-related protein (Sfrp5) is another anti-inflammatory adipokine that participates in the pathogenesis of insulin resistance, DM2, dyslipidemia, obesity, and atherosclerotic cardiovascular disease. For the achievement of this purpose, Sfrp5 acts principally by hindering the Wnt signaling pathway $[2,90,91]$.

Another adipokine, apelin is an endogenous peptide, well-known as a ligand of the orphan G protein-coupled receptor APJ. Apelinergic system might play role in hypertension, cardiac contractility, heart failure, DM2, and obesity. Signal transduction pathways-PI3K/Akt, extracellular signal-regulated kinase (ERK), MAPK, and endothelial NO synthase (eNOS) might be proposed as mechanisms underlying the preventive impacts of apelinergic system in CVDs [92,93].

Osteopontin is a cytokine with pro-inflammatory functions. Activation of downstream signaling pathways, comprising MAPK, ERK, c-Jun N-terminal kinases (JNK), and the PI3K/Akt pathway via osteopontin is witnessed in the protection of CVDs [94].

BATokines are released from brown adipose tissue (BAT). These adipokines protect against obesity and cardiometabolic disorders by regulating BAT function. Most of them have a role in BAT hypertrophy and hyperplasia, vascularization, and blood flow, processes that are related to BAT recruitment when thermogenic activity is increased. Batokines can affect systemic metabolism and supply the beneficial metabolic impact of BAT activation [95].

\section{Adipokines, Obesity, and Cardiometabolic Diseases}

Disorders in adipose tissue lead to a change in the secretory profile of adipokines, which is the hallmark of metabolic dysfunction. An imbalance between the formations of pro- and anti-inflammatory adipokines contribute to cardiometabolic disease and CVDs complications. Furthermore, the process that triggers the dysregulation of adipokines is complex and unknown. For example, one study shows that adipose tissue hypoxia triggers the adiponectin imbalance, and they describe an inverse relationship between blood levels of adiponectin and hemoglobin in obese men [96].

In certain conditions, such as a permanently positive energy balance, adipose tissue has a functional disorder causing several effects. Fatty acids fill-up the adipocytes and alterations in adipokines' secretion profile, including decreased adiponectin and increased leptin levels [97]. The adiponectin/leptin imbalance increases inflammation and facilitates cholesterol accumulation, which triggers the atherosclerosis process. In this condition, low adiponectin levels prevent the repair of endothelial damage and inhibition of the inflammatory response [55].

It has also been investigated whether the change in the secretory profile of adipokines and thus metabolic health depends on the depot in which fat is stored viscerally or subcutaneously, and how this storage increases hypertrophy compared to hyperplasia. Besides, one study showed that general and visceral obesity, but not subcutaneous obesity, is related to the proinflammatory adipokine profile. It was also observed that metabolic health is more related to this adipokine profile than to total adipose tissue mass. However, since all volunteers had clinically manifest vascular disease, the results may not reflect all obese populations [98].

It is known that BMI does not reflect abdominal obesity properly. Also, abdominal obesity means an excessive accumulation of subcutaneous and visceral fat tissue. These large deposits differ in their adipogenic, lipolytic, and lipogenic capacities, and their secretory profiles (adipokines, cytokines, and other characteristic factors). It should be emphasized that visceral adipose tissue is metabolically more active than subcutaneous adipose tissue, and its dysfunction has been reported to acts as a predictor of cardiometabolic health [99]. Several anthropometric measures such as waist circumference, sagittal abdominal diameter, and waist/hip ratio are used to assess abdominal fat. It has been reported that the correlation between these three measurements of visceral fat and CVD 
risk factors, has been established previously [100]. Studies have also shown that higher visceral fat (measured by waist circumference or waist to hip ratio) is independently associated with lower adiponectin formation [101,102]. Interestingly, in obese individuals with DM2, the adipokines profile may differ from those without DM2. Indeed, one study showed that obese patients with DM2 had significantly higher adiponectin levels compared to non-diabetic and non-obese patients [49].

As mentioned above, the longevity of obesity is as important as obesity itself. It has been shown that the changes in adipokines secretion profile throughout the years in obesity can independently predict the CVDs in individuals with coronary artery disease and diabetes [103]. However, the association was non-linear and dependent on BMI values. It is known that the different types of obesity have different effects on the adipokines secretory profile. Thus, individuals with central obesity had increased pro-inflammatory adipokines (TNF- $\alpha$, leptin) and decreased anti-inflammatory adipokines (adiponectin), compared to individuals without central obesity [104].

It has been reported that the adipokine profile, which varies by gender, can influence the complications of obesity, as well as its severity and characteristics. However, complications-related obesity may have different gender-specific mechanisms that are associated with some adipokines. As mentioned above, obese females usually have higher leptin levels. Experimental studies have shown that leptin induces hypertension and endothelial dysfunction in female mice via aldosterone-dependent mechanisms [105]. Adiponectin is known to be generally higher in females and its low levels are associated with visceral adiposity. The underlying reasons for higher adiponectin levels in females may be differences in obesity or sex hormones. However, a study in obese Australian Aboriginal women with chronic kidney disease showed that female-gender was not associated with higher adiponectin levels [102].

It is worth mentioning that the contribution of resistin to metabolic disorders is partly due to inflammation. However, it has been reported that increased serum resistin levels have been observed in overweight and obese women, which may lead to metabolic disorders, and it may be associated with minor inflammation [106].

Since metabolically healthy overweight/obese individuals are in some way resistant towards cardiometabolic complications of obesity, variations in their adipokines profile compared to metabolically unhealthy obese individuals are likely. It has been observed that metabolically unhealthy obese individuals have significantly lower leptin levels compared to metabolically healthy obese individuals [107]. However, the adiponectin did not differ between the two groups.

\section{Adipokines, Obesity, and Cardiovascular Diseases}

In general, the role of adipokines in overweight- and obesity-related CVDs is not yet fully understood. One study found that neither adiponectin nor leptin had an independent association with CVDs. However, IL-6-related signaling pathways showed a significant correlation with the occurrence of CVDs [108]. The carotid intima-media thickness (CIMT) has been reported to be a validated marker for the severity of atherosclerosis $[109,110]$. In obese children, the elevation of CIMT has been associated with low levels of adiponectin, higher levels of leptin, increased C-reactive proteins with high sensitivity (hsCRP), higher levels of lipid, and hypertension. However, adiponectin levels showed a negative correlation with BMI and atherogenic factors [111,112].

Different groups and blood levels of adipokines have been found depending on the obese individuals' age. A cohort study showed that obesity was associated with higher leptin, CRP, and IL-6 levels and lower adiponectin levels from age 11 years and higher endothelial markers such as E-selectin and tissue plasminogen activator (tPA), at 15 years and onwards [113]. However, the longevity of obesity is sometimes overlooked when assessing the risk of CVDs and metabolic disorders.

It has been shown that fatty deposits in adolescence and adulthood are associated with higher harmful levels of adipokines and inflammatory biomarkers [113], which aggravates the atherogenic process and consequently raise the CVDs risk. When obesity complications occur, they may adversely affect some already dysregulated adipokines, which in return may worsen these obesity-related 
complications. One study also showed that hypertensive obese women had higher RNA expression of adiponectin than non-hypertensive women despite being anti-hypertensive [114]. Figure 1 indicates the association between "Inflammation" and "Adiponectin"/"Leptin" and heart failure.

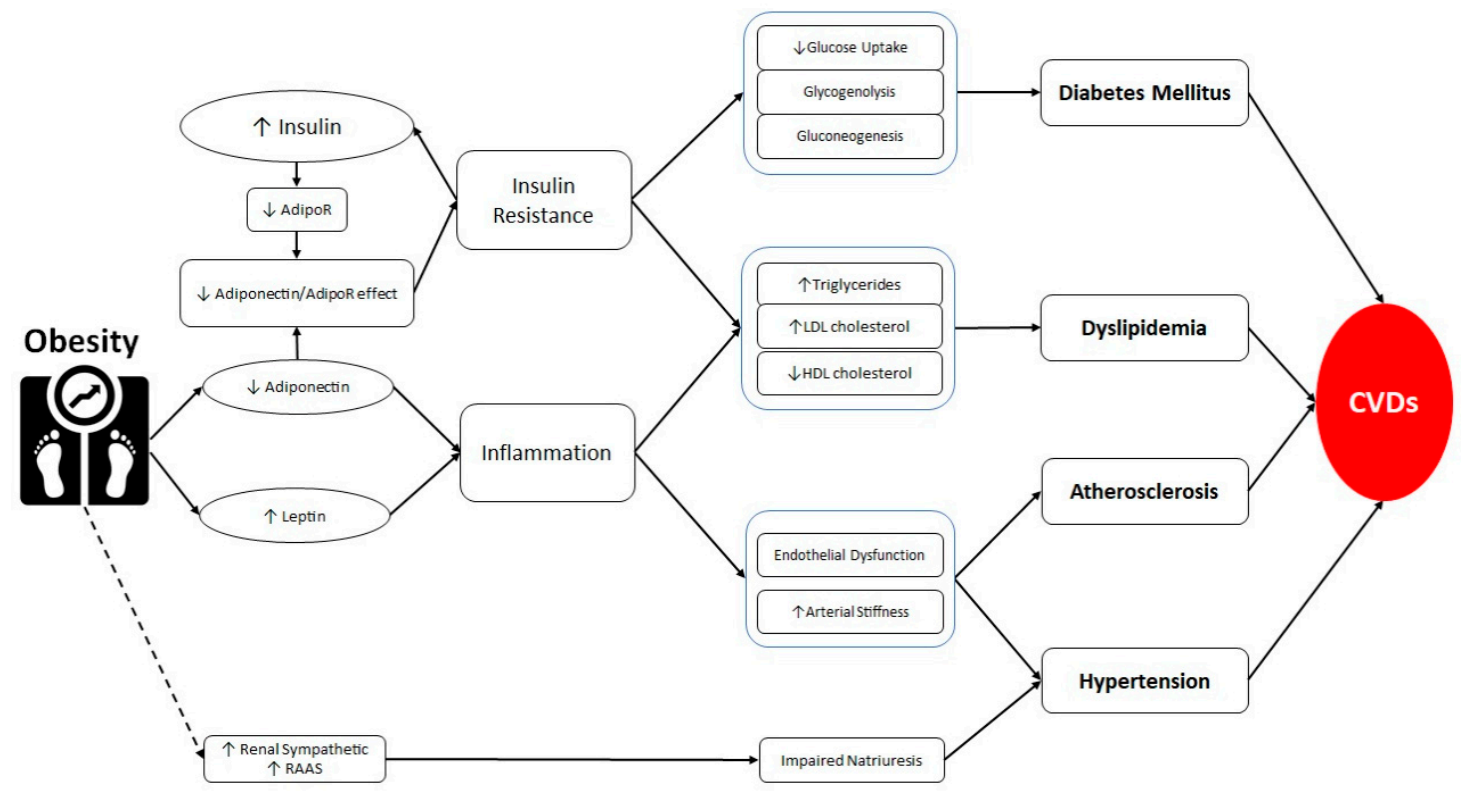

Figure 1. Association between obesity and cardiovascular diseases. Obesity increases leptin and decreases adiponectin. The latter induces insulin resistance via decreasing adiponectin and adiponectin receptor effect. Insulin resistance results in diabetes mellitus. Increased leptin and decreased adiponectin induces inflammation. Both insulin resistance and inflammation induce dyslipidemia. Moreover, inflammation results in atherosclerosis and hypertension through the induction of endothelial dysfunction and increased arterial stiffness. Obesity facilitates hypertension further by impairing the natriuresis balance. The complex of diabetes mellitus, dyslipidemia, atherosclerosis, and hypertension are the primary causes of cardiovascular diseases. AdipoR: adiponectin receptor; CVDs: cardiovascular diseases; RAAS: Renin-Angiotensin-Aldosterone System; AdipoR: Adiponectin Receptor; HDL: high-density lipoprotein; LDL: low-density lipoprotein.

\section{Conclusions}

It is now widely accepted that obesity affects metabolic health and increases the risk of CVDs. After increasing in adipose tissue, several changes in the anatomical structures and heart tissue function can occur even in metabolic disorders-free individuals. In addition, both the incidence and mortality rates of cardiometabolic diseases and CVDs are significantly increased in the obese population. However, controversial studies suggest that obesity does not increase the risk of CVDs in people who are free of metabolic disorders, while some studies with long follow-up periods have shown otherwise. This research area needs more comprehensive studies considering that this subgroup of obese individuals is at risk of being overlooked during medical practice.

As mentioned, adipokines and metabolites secreted by adipocytes play a central role in developing CVDs and metabolic diseases associated with obesity. Most importantly, the mechanisms involved in CVDs are attacked by the binding of adipokines to their receptors. However, the relationship of these molecules to obesity and obesity-associated diseases is still unclear. Besides, several studies reported that changes in adipokines in unhealthy metabolic patients are associated with obesity, while some studies confirmed this association in both healthy and unhealthy obese people. The elucidation of the mechanisms involved in developing inflammatory and metabolic disorders and CVDs is necessary for therapeutic approaches against the increasing epidemics of obesity and related diseases. Besides, the alterations in adipokine secretion profile in metabolically healthy and unhealthy obese individuals may be the primary tool to find protective factors against the development of obesity-related metabolic 
diseases and CVDs. However, given the vast number of adipokines and their different functions, further efforts and studies seem to be necessary to obtain a better picture of adipokines in obesity and obesity-related disorders.

In summary, although obesity has been identified for years as one of the significant risk factors of CVDs, unanswered scientific questions need to be addressed for this association. The discovery of sequenced genomes and biomarkers of obesity and its co-morbidities in healthy metabolic patients is an excellent strategy to prevent CVDs.

Author Contributions: T.F., M.S. and S.S. designed the study. T.F., S.L., A.M.P.-S., M.A., M.T., M.S. and S.S. contributed to the collection of data, to the writing of the manuscript, and to designing tables and figures. S.S. and M.S. revised the manuscript. All authors have read and agreed to the published version of the manuscript.

Funding: This research received no external funding.

Conflicts of Interest: The authors declare no conflict of interest.

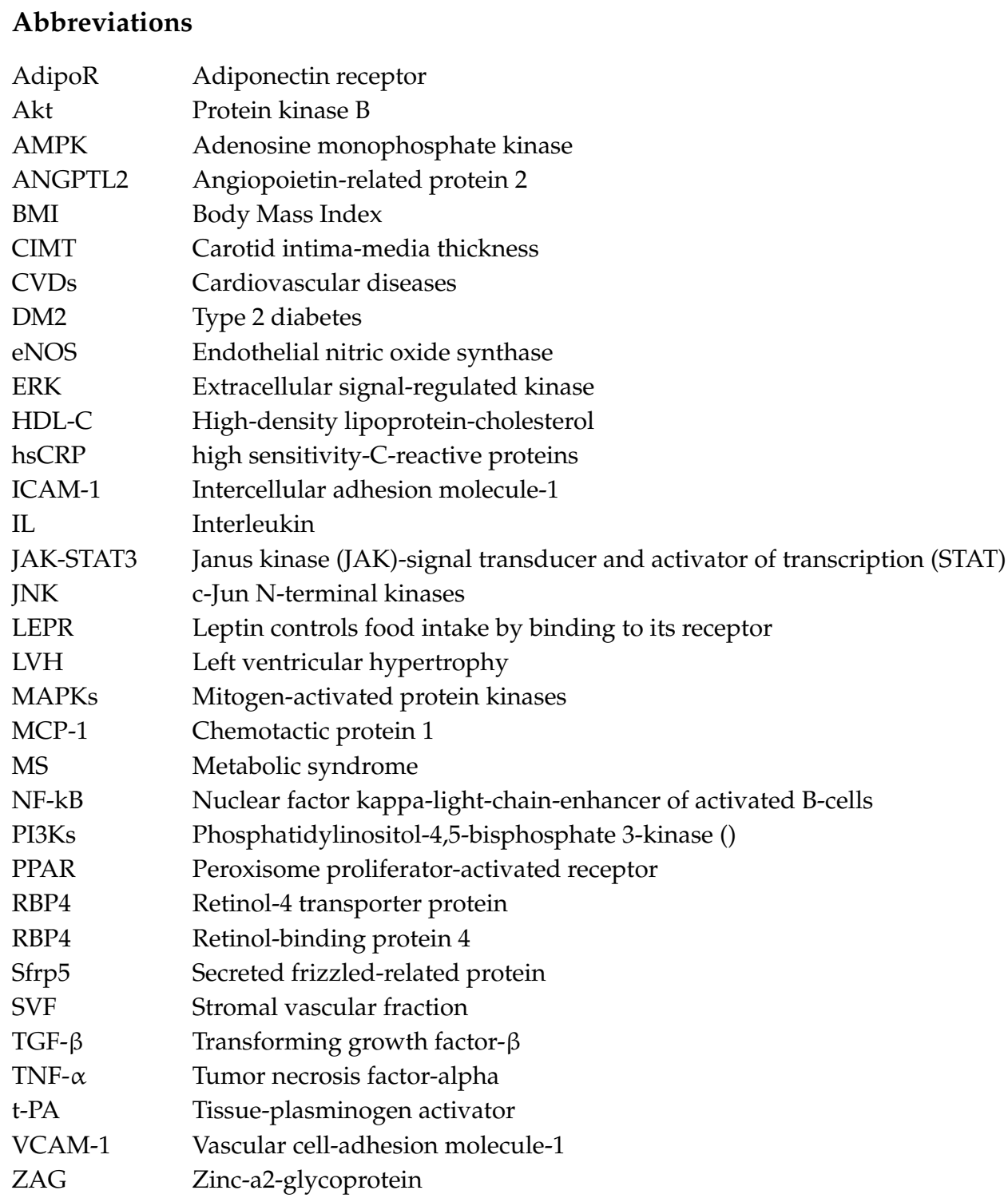




\section{References}

1. Guariguata, L.; Whiting, D.R.; Hambleton, I.; Beagley, J.; Linnenkamp, U.; Shaw, J.E. Global estimates of diabetes prevalence for 2013 and projections for 2035. Diabetes Res. Clin. Pract. 2014, 103, 137-149. [CrossRef] [PubMed]

2. Zhang, Y.; Guan, H.; Fu, Y.; Wang, X.; Bai, L.; Zhao, S.; Liu, E. Effects of SFRP4 overexpression on the production of adipokines in transgenic mice. Adipocyte 2020, 9, 374-383. [CrossRef] [PubMed]

3. Ng, M.; Fleming, T.; Robinson, M.; Thomson, B.; Graetz, N.; Margono, C.; Mullany, E.C.; Biryukov, S.; Abbafati, C.; Abera, S.F.; et al. Global, regional, and national prevalence of overweight and obesity in children and adults during 1980-2013: A systematic analysis for the Global Burden of Disease Study 2013. Lancet 2014, 384, 766-781. [CrossRef]

4. Ahima, R.S.; Flier, J.S. Adipose tissue as an endocrine organ. Trends Endocrinol. Metab. TEM 2000, 11, 327-332. [CrossRef]

5. Poirier, P.; Martin, J.; Marceau, P.; Biron, S.; Marceau, S. Impact of bariatric surgery on cardiac structure, function and clinical manifestations in morbid obesity. Expert Rev. Cardiovasc. Ther. 2004, 2, 193-201. [CrossRef] [PubMed]

6. Poirier, P.; Giles, T.D.; Bray, G.A.; Hong, Y.; Stern, J.S.; Pi-Sunyer, F.X.; Eckel, R.H. Obesity and cardiovascular disease: Pathophysiology, evaluation, and effect of weight loss: An update of the 1997 American Heart Association Scientific Statement on Obesity and Heart Disease from the Obesity Committee of the Council on Nutrition, Physical Activity, and Metabolism. Circ. Res. 2006, 113, 898-918. [CrossRef]

7. Murawska-Cialowicz, E. Adipose tissue-Morphological and biochemical characteristic of different depots. Postepy Hig. Med. Dosw. 2017, 71, 466-484. [CrossRef] [PubMed]

8. Esler, M.; Straznicky, N.; Eikelis, N.; Masuo, K.; Lambert, G.; Lambert, E. Mechanisms of sympathetic activation in obesity-related hypertension. Hypertension 2006, 48, 787-796. [CrossRef]

9. Nakamura, K.; Fuster, J.J.; Walsh, K. Adipokines: A link between obesity and cardiovascular disease. J. Cardiol. 2014, 63, 250-259. [CrossRef]

10. Samaras, K.; Botelho, N.K.; Chisholm, D.J.; Lord, R.V. Subcutaneous and visceral adipose tissue gene expression of serum adipokines that predict type 2 diabetes. Obes. Res. Clin. Pract. 2010, 18, 884-889. [CrossRef]

11. Chatterjee, T.K.; Stoll, L.L.; Denning, G.M.; Harrelson, A.; Blomkalns, A.L.; Idelman, G.; Rothenberg, F.G.; Neltner, B.; Romig-Martin, S.A.; Dickson, E.W. Proinflammatory phenotype of perivascular adipocytes: Influence of high-fat feeding. Circ. Res. 2009, 104, 541-549. [CrossRef]

12. Francisco, V.; Pino, J.; Gonzalez-Gay, M.A.; Mera, A.; Lago, F.; Gómez, R.; Mobasheri, A.; Gualillo, O. Adipokines and inflammation: Is it a question of weight? Br. J. Pharmacol. 2018, 175, 1569-1579. [CrossRef] [PubMed]

13. Meiliana, A.; Wijaya, A.; As'ad Armyn, S. The Relationship of Proinflammatory and Antiinflammatory Adipokines in the Development of Metabolic Syndrome in Centrally Obese Men. Indones. Biomed. J. 2010, 2, 118. [CrossRef]

14. Samarghandian, S.; Borji, A.; Farkhondeh, T. Evaluation of antidiabetic activity of carnosol (phenolic diterpene in rosemary) in streptozotocin-induced diabetic rats. Cardiovasc Haematol Disord Drug Targets 2017, 17, 11-17. [CrossRef]

15. Samarghandian, S.; Azimi-Nezhad, M.; Farkhondeh, T. Immunomodulatory and antioxidant effects of saffron aqueous extract (Crocus sativus L.) on streptozotocin-induced diabetes in rats. Indian Heart J. 2017, 69, 151-159. [CrossRef]

16. Samarghandian, S.; Azimi-Nezhad, M.; Farkhondeh, T. Catechin treatment ameliorates diabetes and its complications in streptozotocin-induced diabetic rats. Dose-Response 2017, 15. [CrossRef]

17. Chhezom, K.; Arslan, M.I.; Hoque, M.M.; Biswas, S.K. Biomarkers of cardiovascular and metabolic diseases in otherwise healthy overweight subjects in Bangladesh. Diabetes Metab. Syndr. Clin. Res. Rev. 2017, 11, S381-S384. [CrossRef] [PubMed]

18. Rijks, J.; Karnebeek, K.; van Dijk, J.-W.; Dorenbos, E.; Gerver, W.-J.; Stouthart, P.; Plat, J.; Vreugdenhil, A. Glycaemic profiles of children with overweight and obesity in free-living conditions in association with cardiometabolic risk. Sci. Rep. 2016, 6, 1-9. [CrossRef] [PubMed] 
19. Araújo, A.; Santos, A.; Prado, W. Body composition of obese adolescents: Association between adiposity indicators and cardiometabolic risk factors. J. Hum. Nutr. Diet. 2017, 30, 193-202. [CrossRef] [PubMed]

20. Hirko, K.A.; Kantor, E.D.; Cohen, S.S.; Blot, W.J.; Stampfer, M.J.; Signorello, L.B. Body mass index in young adulthood, obesity trajectory, and premature mortality. Am. J. Epidemiol. 2015, 182, 441-450. [CrossRef]

21. Bornfeldt, K.E.; Tabas, I. Insulin resistance, hyperglycemia, and atherosclerosis. Cell Metabol. 2011, 14, 575-585. [CrossRef] [PubMed]

22. Bulut, C.; Helvaci, A.; Adas, M.; Ozsoy, N.; Bayyigit, A. The relationship between left ventricular mass and insulin resistance in obese patients. Indian Heart J. 2016, 68, 507-512. [CrossRef]

23. Hirsch, K.R.; Smith-Ryan, A.E.; Blue, M.N.M.; Mock, M.G.; Trexler, E.T.; Ondrak, K.S. Metabolic characterization of overweight and obese adults. Physician Sports Med. 2016, 44, 362-372. [CrossRef]

24. Al-Sendi, A.M.; Shetty, P.; Musaiger, A.O. Anthropometric and body composition indicators of Bahraini adolescents. Ann. Hum. Biol. 2003, 30, 367-379. [CrossRef] [PubMed]

25. Grundy, S.M.; Pasternak, R.; Greenland, P.; Smith, S., Jr.; Fuster, V. Assessment of cardiovascular risk by use of multiple-risk-factor assessment equations: A statement for healthcare professionals from the American Heart Association and the American College of Cardiology. Circulation 1999, 34, 1348-1359. [CrossRef]

26. Bundhun, P.K.; Wu, Z.J.; Chen, M.-H.J.M. Impact of modifiable cardiovascular risk factors on mortality after percutaneous coronary intervention: A systematic review and meta-analysis of 100 studies. Medicine 2015, 94, e2313. [CrossRef]

27. Cho, E.; Manson, J.E.; Stampfer, M.J.; Solomon, C.G.; Colditz, G.A.; Speizer, F.E.; Willett, W.C.; Hu, F.B. A prospective study of obesity and risk of coronary heart disease among diabetic women. Diabetes Care 2002, 25, 1142-1148. [CrossRef]

28. Wolk, R.; Berger, P.; Lennon, R.J.; Brilakis, E.S.; Somers, V.K. Body mass index: A risk factor for unstable angina and myocardial infarction in patients with angiographically confirmed coronary artery disease. Circ. Res. 2003, 108, 2206-2211. [CrossRef]

29. de Castro Pimentel, A.; Scorsatto, M.; de Oliveira, G.M.M.; Rosa, G.; Luiz, R.R. Characterization of metabolically healthy obese Brazilians and cardiovascular risk prediction. Nutrition 2015, 31, 827-833. [CrossRef]

30. Pascual, M.; Pascual, D.; Soria, F.; Vicente, T.; Hernandez, A.; Tebar, F.; Valdes, M.J.H. Effects of isolated obesity on systolic and diastolic left ventricular function. Heart 2003, 89, 1152-1156. [CrossRef]

31. Alpert, M.; Alexander, J.; Chakko, S. Obesity and ventricular function in man: Systolic function. Heart Lung Obes. 1998, 1, 77-94.

32. Alexander, J.K. Blood volume, cardiac output, and distribution of systemic blood flow in extreme obesity. Cardiovasc. Res. Cent. Bull. 1962, 1, 39-44.

33. Alpert, M.A.; Lambert, C.R.; Panayiotou, H.; Terry, B.E.; Cohen, M.V.; Massey, C.V.; Hashimi, M.W.; Mukerji, V. Relation of duration of morbid obesity to left ventricular mass, systolic function, and diastolic filling, and effect of weight loss. Am. J. Prev. Cardiol. 1995, 76, 1194-1197. [CrossRef]

34. Sahasrabuddhe, A.; Pitale, S.; Dhoble, J.; Sagdeo, M. Cardiac diastolic dysfunction and regional body fat distribution in insulin resistant peripubertal obese males. J. Assoc. Physicians India 2016, 64, 20.

35. Broussard, J.L.; Nelson, M.D.; Kolka, C.M.; Bediako, I.A.; Paszkiewicz, R.L.; Smith, L.; Szczepaniak, E.W.; Stefanovski, D.; Szczepaniak, L.S.; Bergman, R.N. Rapid development of cardiac dysfunction in a canine model of insulin resistance and moderate obesity. Diabetologia 2016, 59, 197-207. [CrossRef] [PubMed]

36. McGavock, J.M.; Victor, R.G.; Unger, R.H.; Szczepaniak, L.S. Adiposity of the heart*, revisited. Ann. Intern. Med. 2006, 144, 517-524. [CrossRef]

37. Horwich, T.B.; Fonarow, G.C.; Hamilton, M.A.; MacLellan, W.R.; Woo, M.A.; Tillisch, J.H. The relationship between obesity and mortality in patients with heart failure. J. Am. Coll. Cardiol. 2001, 38, 789-795. [CrossRef]

38. Sharma, A.; Lavie, C.J.; Borer, J.S.; Vallakati, A.; Goel, S.; Lopez-Jimenez, F.; Arbab-Zadeh, A.; Mukherjee, D.; Lazar, J.M. Meta-analysis of the relation of body mass index to all-cause and cardiovascular mortality and hospitalization in patients with chronic heart failure. Am. J. Cardiol. 2015, 115, 1428-1434. [CrossRef]

39. Joyce, E.; Lala, A.; Stevens, S.R.; Cooper, L.B.; AbouEzzeddine, O.F.; Groarke, J.D.; Grodin, J.L.; Braunwald, E.; Anstrom, K.J.; Redfield, M.M. Prevalence, profile, and prognosis of severe obesity in contemporary hospitalized heart failure trial populations. JACC Heart Fail. 2016, 4, 923-931. [CrossRef]

40. Wang, T.J.; Parise, H.; Levy, D.; D’Agostino, R.B.; Wolf, P.A.; Vasan, R.S.; Benjamin, E.J. Obesity and the risk of new-onset atrial fibrillation. JAMA 2004, 292, 2471-2477. [CrossRef] [PubMed] 
41. Thanassoulis, G.; Massaro, J.M.; O’Donnell, C.J.; Hoffmann, U.; Levy, D.; Ellinor, P.T.; Wang, T.J.; Schnabel, R.B.; Vasan, R.S.; Fox, C.S. Pericardial fat is associated with prevalent atrial fibrillation: The Framingham Heart Study. Circ. Arrhythmia Electrophysiol. 2010, 3, 345-350. [CrossRef] [PubMed]

42. Pérez-Pevida, B.; Díaz-Gutiérrez, J.; Miras, A.D.; Silva, C.; Romero, S.; Salvador, J.; Escalada, J.; Frühbeck, G. High body adiposity drives glucose intolerance and increases cardiovascular risk in normoglycemic subjects. Obes. Res. Clin. Pract. 2018, 26, 672-682. [CrossRef]

43. Clifton, P.M. Relationship between changes in fat and lean depots following weight loss and changes in cardiovascular disease risk markers. J. Am. Heart Assoc. 2018, 7, e008675. [CrossRef]

44. Oliveros, E.; Somers, V.K.; Sochor, O.; Goel, K.; Lopez-Jimenez, F. The concept of normal weight obesity. Prog. Cardiovasc. Dis. 2014, 56, 426-433. [CrossRef]

45. Kaur, A.; Johnston, D.G.; Godsland, I.F. Does metabolic health in overweight and obesity persist?-Individual variation and cardiovascular mortality over two decades. Eur. J. Endocrinol. 2016, 175, 133-143. [CrossRef]

46. Voulgari, C.; Tentolouris, N.; Dilaveris, P.; Tousoulis, D.; Katsilambros, N.; Stefanadis, C. Increased heart failure risk in normal-weight people with metabolic syndrome compared with metabolically healthy obese individuals. J. Am. Coll. Cardiol. 2011, 58, 1343-1350. [CrossRef] [PubMed]

47. Hosseinpanah, F.; Barzin, M.; Sheikholeslami, F.; Azizi, F. Effect of different obesity phenotypes on cardiovascular events in Tehran Lipid and Glucose Study (TLGS). Am. J. Cardiol. 2011, 107, 412-416. [CrossRef]

48. Mirzaei, B.; Abdi, H.; Serahati, S.; Barzin, M.; Niroomand, M.; Azizi, F.; Hosseinpanah, F.J.A. Cardiovascular risk in different obesity phenotypes over a decade follow-up: Tehran Lipid and Glucose Study. Atherosclerosis 2017, 258, 65-71. [CrossRef]

49. Kouvari, M.; Panagiotakos, D.B.; Yannakoulia, M.; Georgousopoulou, E.; Critselis, E.; Chrysohoou, C.; Tousoulis, D.; Pitsavos, C.; Investigators, A.S. Transition from metabolically benign to metabolically unhealthy obesity and 10-year cardiovascular disease incidence: The ATTICA cohort study. Metabolism 2019, 93, 18-24. [CrossRef]

50. Lehr, S.; Hartwig, S.; Sell, H. Adipokines: A treasure trove for the discovery of biomarkers for metabolic disorders. Proteom. Clin. Appl. 2012, 6, 91-101. [CrossRef] [PubMed]

51. Zorena, K.; Jachimowicz-Duda, O.; Ślęzak, D.; Robakowska, M.; Mrugacz, M. Adipokines and Obesity. Potential Link to Metabolic Disorders and Chronic Complications. Int. J. Mol. Sci. 2020, 21, 3570. [CrossRef]

52. Fasshauer, M.; Blüher, M. Adipokines in health and disease. Trends Pharm. Sci. 2015, 36, 461-470. [CrossRef] [PubMed]

53. Kumari, R.; Kumar, S.; Kant, R. An update on metabolic syndrome: Metabolic risk markers and adipokines in the development of metabolic syndrome. Diabetes Metab. Syndr. 2019, 13, 2409-2417. [CrossRef]

54. Pujanek, M.; Bronisz, A.; Małecki, P.; Junik, R. Pathomechanisms of the development of obesity in some endocrinopathies-An overview. Endokrynol. Pol. 2013, 64, 150-155. [PubMed]

55. Ntaios, G.; Gatselis, N.K.; Makaritsis, K.; Dalekos, G.N. Adipokines as mediators of endothelial function and atherosclerosis. Atherosclerosis 2013, 227, 216-221. [CrossRef]

56. Jung, C.H.; Kim, M.-S. Molecular mechanisms of central leptin resistance in obesity. Arch. Pharm. Res. 2013, 36, 201-207. [CrossRef]

57. Vu, J.P.; Larauche, M.; Flores, M.; Luong, L.; Norris, J.; Oh, S.; Liang, L.J.; Waschek, J.; Pisegna, J.R.; Germano, P.M. Regulation of Appetite, Body Composition, and Metabolic Hormones by Vasoactive Intestinal Polypeptide (VIP). J. Mol. Neurosci. 2015, 56, 377-387. [CrossRef]

58. Friedman, J.M. Leptin, leptin receptors, and the control of body weight. Nutr. Rev. 1998, 56, S38-S46. [CrossRef]

59. Yadav, A.; Kataria, M.A.; Saini, V.; Yadav, A. Role of leptin and adiponectin in insulin resistance. Clin. Chim. Acta 2013, 417, 80-84. [CrossRef]

60. Coelho, M.; Oliveira, T.; Fernandes, R. Biochemistry of adipose tissue: An endocrine organ. Arch. Med. Sci. 2013, 9, 191. [CrossRef]

61. Lenz, A.; Diamond, F.B., Jr. Obesity: The hormonal milieu. Curr. Opin. Endocrinol. Diabetes Obes. 2008, 15, 9-20. [CrossRef]

62. Lago, F.; Gómez, R.; Gómez-Reino, J.J.; Dieguez, C.; Gualillo, O. Adipokines as novel modulators of lipid metabolism. Trends Biochem. Sci. 2009, 34, 500-510. [CrossRef] 
63. Bray, G.A.; Clearfield, M.B.; Fintel, D.J.; Nelinson, D.S. Overweight and obesity: The pathogenesis of cardiometabolic risk. Clin. Cornerstone 2009, 9, 30-42. [CrossRef]

64. Yamauchi, T.; Kadowaki, T. Physiological and pathophysiological roles of adiponectin and adiponectin receptors in the integrated regulation of metabolic and cardiovascular diseases. Int. J. Obes. Suppl. 2008, 32, S13-S18. [CrossRef]

65. Yamauchi, T.; Kadowaki, T. Adiponectin receptor as a key player in healthy longevity and obesity-related diseases. Cell Metab. 2013, 17, 185-196. [CrossRef]

66. Luo, N.; Chung, B.H.; Wang, X.; Klein, R.L.; Tang, C.-K.; Garvey, W.T.; Fu, Y.J.A. Enhanced adiponectin actions by overexpression of adiponectin receptor 1 in macrophages. Atherosclerosis 2013, 228, 124-135. [CrossRef] [PubMed]

67. de Oliveira Leal, V.; Mafra, D. Adipokines in obesity. Clin. Chimica Acta 2013, 419, 87-94. [CrossRef]

68. Anandaraj, A.A.; Mahin Syed Ismail, P.; Mohammed Namis, S.; Jadallah Bajnaid, Y.; B Shetty, S.; M Almutairi, K. Association of selected Adipocytokines and Inflammatory markers on Body Mass Index in Type 2 Diabetes patients in Saudi Arabia and as risk factors to cardiovascular disease. Curr. Diabetes Rev. 2017, 13, 330-335. [CrossRef]

69. Tripathi, D.; Kant, S.; Pandey, S.; Ehtesham, N.Z. Resistin in metabolism, inflammation, and disease. FEBS J. 2020, 287, 3141-3149. [CrossRef]

70. Dasari, R.; Raghunath, V. Obesity and Type II diabetes mellitus: Is resistin the link? J. Diabetes Endocr. Pract. 2018, 1, 1-8. [CrossRef]

71. Singh, A.K.; Tiwari, S.; Gupta, A.; Natu, S.M.; Mittal, B.; Pant, A.B.J.M.S.; Disorders, R. Association of resistin with metabolic syndrome in Indian subjects. Metab. Syndr. Relat. Dis. 2012, 10, 286-291. [CrossRef]

72. Onuma, H.; Tabara, Y.; Kawamura, R.; Ohashi, J.; Nishida, W.; Takata, Y.; Ochi, M.; Nishimiya, T.; Kawamoto, R.; Kohara, K. Plasma resistin is associated with single nucleotide polymorphisms of a possible resistin receptor, the decorin gene, in the general Japanese population. Diabetes 2013, 62, 649-652. [CrossRef] [PubMed]

73. Schwartz, D.R.; Lazar, M.A. Human resistin: Found in translation from mouse to man. Trends Endocrinol. Metab. 2011, 22, 259-265. [CrossRef] [PubMed]

74. Tsiotra, P.C.; Boutati, E.; Dimitriadis, G.; Raptis, S.A. High insulin and leptin increase resistin and inflammatory cytokine production from human mononuclear cells. BioMed Res. Int. 2012, 2013. [CrossRef]

75. Khera, A.V.; Qamar, A.; Murphy, S.A.; Cannon, C.P.; Sabatine, M.S.; Rader, D.J. On-Statin Resistin, Leptin, and Risk of Recurrent Coronary Events After Hospitalization for an Acute Coronary Syndrome (from the Pravastatin or Atorvastatin Evaluation and Infection Therapy-Thrombolysis in Myocardial Infarction 22 Study). Am. J. Cardiol. 2015, 116, 694-698. [CrossRef]

76. Bik, W.; Ostrowski, J.; Baranowska-Bik, A.; Wolinska-Witort, E.; Bialkowska, M.; Martynska, L.; Baranowska, B. Adipokines and genetic factors in overweight or obese but metabolically healthy Polish women. Neuroendocrinol. Lett. 2010, 31, 497-506.

77. Telle-Hansen, V.; Halvorsen, B.; Dalen, K.; Narverud, I.; Wesseltoft-Rao, N.; Granlund, L.; Ulven, S.; Holven, K. Altered expression of genes involved in lipid metabolism in obese subjects with unfavourable phenotype. Genes Nutr. 2013, 8, 425-434. [CrossRef]

78. Jager, J.; Grémeaux, T.; Gonzalez, T.; Bonnafous, S.; Debard, C.; Laville, M.; Vidal, H.; Tran, A.; Gual, P.; Le Marchand-Brustel, Y. Tp12 Kinase Is Upregulated in Adipose Tissue in Obesity and May Mediate Interleukin-1 $\beta$ and Tumor Necrosis Factor- $\alpha$ Effects on Extracellular Signal-Regulated Kinase Activation and Lipolysis. Diabetes 2010, 59, 61-70. [CrossRef]

79. Balistreri, C.R.; Caruso, C.; Candore, G. The role of adipose tissue and adipokines in obesity-related inflammatory diseases. Mediat. Inflamm 2010, 2010, 802078. [CrossRef]

80. Rull, A.; Camps, J.; Alonso-Villaverde, C.; Joven, J. Insulin resistance, inflammation, and obesity: Role of monocyte chemoattractant protein-1 (orCCL2) in the regulation of metabolism. Mediat. Inflamm 2010, 2010, 326580. [CrossRef] [PubMed]

81. Chang, J.-S.; Chang, C.-C.; Chien, E.Y.; Lin, S.S.; Cheng-Shiuan, T.; Bai, C.-H.; Chao, K.-C. Association between interleukin $1 \beta$ and interleukin 10 concentrations: A cross-sectional study in young adolescents in Taiwan. BMC Pediatr. 2013, 13, 123. [CrossRef] [PubMed]

82. Tan, C.K.; Chong, H.C.; Tan, E.H.; Tan, N.S. Getting 'Smad' about obesity and diabetes. Nutr. Diabetes 2012, 2, e29. [CrossRef] 
83. Yadav, H.; Quijano, C.; Kamaraju, A.K.; Gavrilova, O.; Malek, R.; Chen, W.; Zerfas, P.; Zhigang, D.; Wright, E.C.; Stuelten, C.; et al. Protection from obesity and diabetes by blockade of TGF- $\beta / \mathrm{Smad} 3$ signaling. Cell Metab. 2011, 14, 67-79. [CrossRef] [PubMed]

84. Naaman, C.E.; Grum-Schwensen, B.; Mansouri, A.; Grigorian, M.; Santoni-Rugiu, E.; Hansen, T.; Kriajevska, M.; Schafer, B.W.; Heizmann, C.W.; Lukanidin, E.; et al. Cancer predisposition in mice deficient for the metastasis-associated Mts1 (S100A4) gene. Oncogene 2004, 23, 3670-3680. [CrossRef]

85. Arner, P.; Petrus, P.; Esteve, D.; Boulomié, A.; Näslund, E.; Thorell, A.; Gao, H.; Dahlman, I.; Rydén, M. Screening of potential adipokines identifies S100A4 as a marker of pernicious adipose tissue and insulin resistance. Int. J. Obes. 2018, 42, 2047-2056. [CrossRef] [PubMed]

86. Hou, S.; Jiao, Y.; Yuan, Q.; Zhai, J.; Tian, T.; Sun, K.; Chen, Z.; Wu, Z.; Zhang, J. S100A4 protects mice from high-fat diet-induced obesity and inflammation. Lab. Investig. 2018, 98, 1025-1038. [CrossRef] [PubMed]

87. Aeberli, I.; Biebinger, R.; Lehmann, R.; L'Allemand, D.; Spinas, G.A.; Zimmermann, M.B. Serum retinol-binding protein 4 concentration and its ratio to serum retinol are associated with obesity and metabolic syndrome components in children. J. Clin. Endocrinol. Metab. 2007, 92, 4359-4365. [CrossRef]

88. Pereira, S.S.; Alvarez-Leite, J.I. Adipokines: Biological functions and metabolically healthy obese profile. Recep. Lig. Channel. Res. 2014, 7, 15-25. [CrossRef]

89. Hosseinzadeh-Attar, M.J.; Mahdavi-Mazdeh, M.; Yaseri, M.; Zahed, N.S.; Alipoor, E. Comparative assessment of serum adipokines zinc- $\alpha 2$-glycoprotein and adipose triglyceride lipase, and cardiovascular risk factors between normal weight and obese patients with hemodialysis. Arch. Med. Res. 2017, 48, 459-466. [CrossRef]

90. Tong, S.; Ji, Q.; Du, Y.; Zhu, X.; Zhu, C.; Zhou, Y. Sfrp5/Wnt Pathway: A Protective Regulatory System in Atherosclerotic Cardiovascular Disease. J. Interferon Cytokine Res. 2019, 39, 472-482. [CrossRef]

91. Wang, D.; Zhang, Y.; Shen, C. Research update on the association between SFRP5, an anti-inflammatory adipokine, with obesity, type 2 diabetes mellitus and coronary heart disease. J. Cell. Mol. Med. 2020, 24, 2730-2735. [CrossRef]

92. Wysocka, M.B.; Pietraszek-Gremplewicz, K.; Nowak, D. The Role of Apelin in Cardiovascular Diseases, Obesity and Cancer. Front. Physiol. 2018, 9, 557. [CrossRef]

93. Zhong, J.-C.; Zhang, Z.-Z.; Wang, W.; McKinnie, S.M.K.; Vederas, J.C.; Oudit, G.Y. Targeting the apelin pathway as a novel therapeutic approach for cardiovascular diseases. Biochim. Biophys. Acta (BBA)—Mol. Basis Dis. 2017, 1863, 1942-1950. [CrossRef] [PubMed]

94. Abdelaziz Mohamed, I.; Gadeau, A.-P.; Hasan, A.; Abdulrahman, N.; Mraiche, F. Osteopontin: A Promising Therapeutic Target in Cardiac Fibrosis. Cells 2019, 8, 1558. [CrossRef]

95. Lok, Z.S.Y.; Lyle, A.N. Osteopontin in Vascular Disease. Arter. Thromb Vasc. Biol. 2019, 39, 613-622. [CrossRef] [PubMed]

96. Streeter, E.A.; Squires, E.C.; Leonard, W.R.; Tarskaia, L.A.; Klimova, T.M.; Fedorova, V.I.; Baltakhinova, M.E.; Krivoshapkin, V.G.; Snodgrass, J.J. Adiponectin, hemoglobin, and cardiovascular risk in an indigenous siberian population. Am. J. Hum. Biol. 2016, 28, 580-583. [CrossRef]

97. Adamczak, M.; Wiecek, A. The adipose tissue as an endocrine organ. Semin Nephrol. 2013, 33, 2-13. [CrossRef]

98. Schrover, I.M.; van der Graaf, Y.; Spiering, W.; Visseren, F.L. The relation between body fat distribution, plasma concentrations of adipokines and the metabolic syndrome in patients with clinically manifest vascular disease. Eur. J. Prev. Cardiol. 2018, 25, 1548-1557. [CrossRef]

99. Goran, M.I.; Gower, B.A. Relation between visceral fat and disease risk in children and adolescents. Am. J. Clin. Nutr. 1999, 70, 149S-156S. [CrossRef]

100. Weber, D.R.; Katz, L.E.L.; Zemel, B.S.; Gallagher, P.R.; Murphy, K.M.; Dumser, S.M.; Lipman, T.H.J.D.R. Anthropometric measures of abdominal adiposity for the identification of cardiometabolic risk factors in adolescents. Diabetes Res. Clin. Pract. 2014, 103, e14-e17. [CrossRef]

101. Ortiz Segura, M.d.C.; del Río Navarro, B.E.; Rodriguez Espino, B.A.; Marchat, L.A.; Sanchez Munoz, F.; Villafaña, S.; Hong, E.; Meza-Cuenca, F.; Mailloux Salinas, P.; Bolaños-Jiménez, F. Abnormality of adipokines and endothelial dysfunction in Mexican obese adolescents with insulin resistance. Endocr. Res. 2017, 42, 252-259. [CrossRef]

102. Hughes, J.; O’Dea, K.; Piera, K.; Barzi, F.; Cass, A.; Hoy, W.; MacIsaac, R.; Maple-Brown, L.J. Associations of serum adiponectin with markers of cardio-metabolic disease risk in Indigenous Australian adults with good health, diabetes and chronic kidney disease. Obes. Res. Clin. Pract. 2016, 10, 659-672. [CrossRef] 
103. Wolk, R.; Bertolet, M.; Singh, P.; Brooks, M.M.; Pratley, R.E.; Frye, R.L.; Mooradian, A.D.; Rutter, M.K.; Calvin, A.D.; Chaitman, B.R. Prognostic value of adipokines in predicting cardiovascular outcome: Explaining the obesity paradox. Mayo Clin. Proc. 2016, 91, 858-866. [CrossRef]

104. Supriya, R.; Tam, B.T.; Angus, P.Y.; Lee, P.H.; Lai, C.W.; Cheng, K.K.; Yau, S.Y.; Chan, L.W.; Yung, B.Y.; Sheridan, $\mathrm{S}$. Adipokines demonstrate the interacting influence of central obesity with other cardiometabolic risk factors of metabolic syndrome in Hong Kong Chinese adults. PLoS ONE 2018, 13, e0201585. [CrossRef]

105. Huby, A.-C.; Otvos, L., Jr.; Belin de Chantemèle, E.J. Leptin induces hypertension and endothelial dysfunction via aldosterone-dependent mechanisms in obese female mice. Hypertension 2016, 67, 1020-1028. [CrossRef] [PubMed]

106. Alissa, E.M.; Alzughaibi, L.S.; Marzouki, Z.M.J.C.; Lipids, P.O. Association between serum resistin, adiposity measures and inflammatory makers in women without cardiovascular diseases. Nutr. Diabetes 2019, 218, 136-140. [CrossRef]

107. Jamar, G.; Caranti, D.A.; de Cassia Cesar, H.; Masquio, D.C.L.; Bandoni, D.H.; Pisani, L.P. Leptin as a cardiovascular risk marker in metabolically healthy obese: Hyperleptinemia in metabolically healthy obese. Appetite 2017, 108, 477-482. [CrossRef]

108. Seven, E.; Husemoen, L.L.; Sehested, T.S.; Ibsen, H.; Wachtell, K.; Linneberg, A.; Jeppesen, J.L. Adipocytokines, C-reactive protein, and cardiovascular disease: A population-based prospective study. PLoS ONE 2015, 10, e0128987. [CrossRef]

109. Salepci, B.; Fidan, A.; Ketenci, S.C.; Parmaksiz, E.T.; Comert, S.S.; Kiral, N.; Akturk, U.A.; Caglayan, B.; Salepci, E. The effect of obstructive sleep apnea syndrome and snoring severity to intima-media thickening of carotid artery. Sleep Breath. Schlaf Atm. 2015, 19, 239-246. [CrossRef] [PubMed]

110. Lester, S.J.; Eleid, M.F.; Khandheria, B.K.; Hurst, R.T. Carotid intima-media thickness and coronary artery calcium score as indications of subclinical atherosclerosis. Mayo Clin. Proc. 2009, 84, 229-233. [CrossRef] [PubMed]

111. Rumińska, M.; Majcher, A.; Pyrżak, B.; Czerwonogrodzka-Senczyna, A.; Brzewski, M.; Demkow, U. Cardiovascular risk factors in obese children and adolescents. In Advances in Clinical Science; Springer: Berlin/Heidelberg, Germany, 2015; pp. 39-47.

112. Stroescu, R.; Teofana-Otilia, B.; Doroş, G.; Marazan, M.; Lesovici, M.; Mãrginean, O. Correlation between adipokines and carotid intima media thickness in a group of obese Romanian children: Is small for gestational age status an independent factor for cardiovascular risk? Arch. Endocrinol. Metab. 2017, 61, 14-20. [CrossRef] [PubMed]

113. Murray, E.T.; Hardy, R.; Hughes, A.; Wills, A.; Sattar, N.; Deanfield, J.; Kuh, D.; Whincup, P. Overweight across the life course and adipokines, inflammatory and endothelial markers at age 60-64 years: Evidence from the 1946 birth cohort. Int. J. Obes. 2015, 39, 1010-1018. [CrossRef]

114. Cano-Martínez, L.J.; Marroquín, C.; Coral-Vázquez, R.M.; Méndez, J.P.; Trejo, S.; Pérez, F.J.C.; Pérez-Razo, J.C.; Canto, P. Expression of adipokines and their receptors in adipose tissue of women with class 3 obesity with or without hypertension. Gene 2019, 702, 148-152. [CrossRef]

Sample Availability: Samples of the compounds are not available from the authors.

Publisher's Note: MDPI stays neutral with regard to jurisdictional claims in published maps and institutional affiliations.

(C) 2020 by the authors. Licensee MDPI, Basel, Switzerland. This article is an open access article distributed under the terms and conditions of the Creative Commons Attribution (CC BY) license (http://creativecommons.org/licenses/by/4.0/). 